AperTO - Archivio Istituzionale Open Access dell'Università di Torino

\title{
M-Workplace Learning @ ITC-ILO
}

\section{This is the author's manuscript}

Original Citation:

Availability:

This version is available http://hdl.handle.net/2318/1509343

since 2017-12-05T19:47:18Z

Publisher:

Springer

Terms of use:

Open Access

Anyone can freely access the full text of works made available as "Open Access". Works made available under a Creative Commons license can be used according to the terms and conditions of said license. Use of all other works requires consent of the right holder (author or publisher) if not exempted from copyright protection by the applicable law. 


\section{(2) \\ UNIVERSITÀ DEGLI STUDI DI TORINO}

This is an author version of the contribution published on:

Questa è la versione dell'autore dell'opera:

Barbara Bruschi, M-Workplace Learning @ ITC-ILO, Mobile as a Mainstream Towards Future Challenges in Mobile Learning, Springer International Publishing, 2014, vol. 479, p. 272-286

The definitive version is available at:

La versione definitiva è disponibile alla URL:

http://link.springer.com/chapter/10.1007/978-3-319-13416-1_26 


\title{
M-Workplace Learning @ ITC-ILO
}

\section{Design Thinking for Mobile Learning Interventions at Work}

\author{
Alessia Messuti ${ }^{1,2}$, Tom Wambeke ${ }^{1}$, Marco Kalz ${ }^{3}$, and Barbara Bruschi ${ }^{2}$ \\ ${ }^{1}$ International Training Centre of the International Labour Organization, Turin, Italy \\ ${ }^{2}$ Università degli Studi di Torino, Dipartimento di Filosofia e Scienze dell'Educazione, \\ Turin, Italy \\ ${ }^{3}$ Open University of the Netherlands, Welten Institute, Heerlen, The Netherlands \\ \{a.messuti,t.wambeke\}@itcilo.org, marco.kalz@ou.nl, \\ barbara.bruschi@unito.it
}

\begin{abstract}
The paper describes an applied research project intended to facilitate the learning at/for work of learning and development professionals through mobile learning. In particular, the audience was narrowed to professionals of the International Training Centre of the International Labour Organization, a UN agency based in Turin, Italy. The methodology adopted moved beyond the traditional instructional design towards design thinking, which takes into account five phases (discovery, interpretation, ideation, experimentation and evolution) that help identifying a concrete challenge until building a practical solution. The results covered in this paper represent the first three phases of the design thinking process: discovery, interpretation and ideation. Building on these findings, three workplace learning challenges were identified to be solved through mobile learning: improving knowledge sharing and effective communication at work, facilitating appropriation of learning experiences at work, increasing motivation towards learning at work through game concepts.
\end{abstract}

Keywords: adult learning, mobile learning, workplace learning, continuous learning, informal learning, mobile methods, mobile tools, design thinking.

\section{Introduction}

Workplace learning has become increasingly important in the development of skills in a time of increasing competition as it ensures that workers' skills are constantly renewed and adapted. However, in such context it is difficult to find suitable time for attending formal training sessions and workplace-learning initiatives are often geared towards providing quick access to content-driven instruction. As a result, professional staff are relying more and more on informal initiatives where learning happens at the moment of need.

This paper describes an applied research project intended to facilitate the learning at/for work of learning and development professionals through mobile learning strategies. In particular, the project focus is to seek whether the use of mobile methods and tools can support social and informal learning at the workplace. The audience of 
the research project was narrowed to learning and development professionals working for the training center of the International Labour Organization (ITC-ILO), but we expect that results of this project can inform other organizations.

The International Labour Organization (ILO) is the oldest UN agency, working towards the goal of decent work for all. The unique tripartite structure of the ILO gives an equal voice to workers, employers and governments to ensure that the views of the social partners are closely reflected in labour standards and in shaping policies and programs. In 1964 the ILO identified the need to train people on how to put its values into practice in a real world context, and so it created the International Training Centre (ITC-ILO) in Turin, Italy as its vocational training institute, the only one of its kind in the world. The centre's mission is to be the leading global provider of learning and training for the world of work.

The centre's learning, knowledge sharing and capacity-building activities and programs for governments, workers and employers' organizations are focused in the fields of: rights at work, enterprise, employment and skills development, social protection, social dialogue, labour law and labour administration, workers' and employers' organizations, gender and non-discrimination, sustainable development and governance. With 14.000 participants each year from 192 countries, around half of the centre's work takes place at Turin campus in Italy, while the rest of its training activities take place on the field in developing regions [1]. As a result, ITC-ILO staff is usually traveling to deliver training across the globe, making it more and more difficult for them to attend formal training sessions at the workplace.

Therefore the macro objective of the "M-Workplace Learning @ ITC-ILO" research is to identify effective training modalities that suit the needs of a specific group of workers. The overall project was informed by previous experiences and projects conducted since 2011 by the ITC-ILO which pointed out the potential of mobile methodologies as a means to facilitate learning and knowledge sharing with ITC-ILO beneficiaries, as well as to allow the extended participation of staff in professional, work-based communities [2-3].

\section{$2 \quad$ Methodology}

The methodological approach adopted for this research progressively moved beyond the traditional instructional design towards design thinking methodologies. Design thinking is a structured approach to generate ideas and provide innovative solutions to practical needs [4]. It is a human-centred, collaborative and experimental approach, which begins by understanding the needs and motivation of people, translating them into frameworks and opportunities, solutions and prototypes. However design thinking was originally meant for big corporations, it is possible to use this approach to address any challenge, especially those that focus on the design and development of learning experiences. The approach takes into account five phases that help identifying a concrete challenge until finding and building a practical solution:

- Discovery: framing a practical challenge and defining the audience;

- Interpretation: reviewing the history of the challenge, find common themes and translate them into actionable statements; 
- Ideation: generating as many ideas as possible to serve the identified needs

- Experimentation: creating working prototypes

- Evolution: gathering feedback, determine if the solution met the goals, discuss what could be improved, measure success and document the process [4]

The content of this paper includes results from the first three phases of the design thinking process: discovery, interpretation and ideation. In the next sections we discuss the approach taken into detail.

\subsection{Discovery}

As previously mentioned, the macro objective of the research project is to identify effective learning and training modalities that suit the needs of ITC-ILO learning and development professionals. In order to define the context of the research, an extensive research was conducted between November 2013 and February 2014, including a study of a comprehensive learning needs analysis of staff, a desk review and a series of interviews with learning and development professionals working for different departments. A comprehensive learning needs analysis was conducted at ITC-ILO in 2013 consisting out of three different phases: an online survey to assess individual learning needs, several team meetings to assess team learning needs and focus groups to gather important elements for the organizational learning strategy. The analysis overall objective was to build a learning culture at ITC-ILO workplace settings.

After having analysed data and comments, the first noteworthy fact that emerged from the survey was that $35 \%$ of staff did not engage in any form of training in 2012 ; and almost $50 \%$ of staff did not attend any language training even if the staff generally perceives language competencies as essential to the work at the ITC-ILO. Generally speaking, staff indicated that more investment in alternative learning modalities other than formal training would have been welcome such as: refresher courses, more career development opportunities, more e-Learning opportunities, more informal lunchtime sessions, more staff exchanges among sectors.

A qualitative literature review was done to gain an in-depth-understanding of the "mobile learning" and "workplace learning" concepts, and to identify good practices of using mobile technology for continuous learning at work. The qualitative review was done by using different channels such as academic social networks (Mendeley and Academia.edu), content curation tools (Scoop.it), books and manuals.

As a result, mobile workplace learning has been framed according to the definition by Pimmer \& Pachler: "the processes of coming to know, and of being able to operate successfully in, and across, new and ever changing contexts, including learning for, at and through work, by means of mobile devices" [5]. The definition highlights the importance of mobile learning for knowledge application rather than for knowledge acquisition by stressing the practical aspect of being able to operate successfully across contexts. In addition to this, a review of the five moments of learning need introduced by Gottfredson and Mosher [6] reveals that only three moments are most appropriate for mobile learning: 1) when trying to remember, 2) when things change, 3 ) when something goes wrong. This implies that mobile learning is most suitable for 
performance support rather than being aligned with more traditional modes of learning.

A qualitative field study was conducted to gain an in-depth understanding of (potential) mobile learning practices at ITC-ILO. For this purpose, 26 staff members (42\% men and 58\% women), including senior managers, activity managers, programme assistants, and interns from different departments were interviewed. Visual facilitation techniques were used to facilitate the discussion around the topics of workplace learning, motivation towards training at work, mobile behaviours and interest in connecting mobile technology with learning experiences.

A visual template was used to engage staff during the interviews by writing or drawing. Interviewees were firstly asked to write down their exact job title and then, to reflect on how they could describe it in other words (e.g. what does "activity manager" means to you?). This question was useful to frame the roles, activities, motivations and frustrations of people towards workplace settings. Later on, interviewees were asked to think if attending training was also part of their work life and encouraged to translate their work-related tasks in images by using selected Power Point ClipArts. The result was a collage where the size of images was proportional to the relevance of the tasks performed on a regular basis at the workplace. Staff development training was often present in small percentages (see fig. 1). These collages allowed the visualization of interviewees' work life and made them reflect on the reasons why training is not so relevant, or on the fact that despite their job title, a big portion of their work life is dedicated to time-consuming activities such as email management.

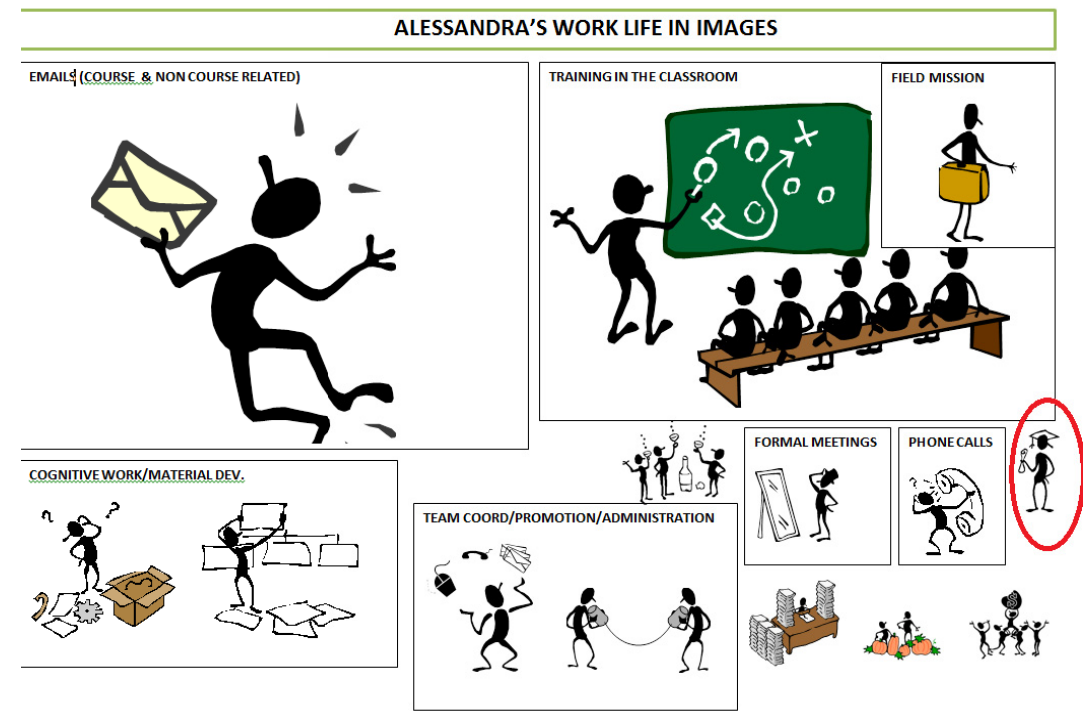

Fig. 1. Visual representation of work-related tasks where the percentage of staff development activities is rather low 
Generally, interviewed staff stressed the fact that learning at work mostly happens through sharing with others, through targeted interaction (individual meetings) and systematic follow-up actions rather than only relying on formal learning interventions. Limited attendance to staff development activities was often connected to time constraints and busy schedules. Despite different learning preferences, they overall agreed on the fact that work-related training should be short in duration but regular, inspirational and collaborative.

Finally, interviewees were asked to give a definition for mobile. Generally speaking, the concept of mobile was associated with a device (mobile phones, tablets, laptops, cameras etc.) and it was difficult to perceive it as a standing alone concept. Although when pushed to think beyond the tool, mobile was overall associated to easy life and support, accessibility, flexibility, new generation, future but also chaos. Interviewees were also encouraged to reflect on mobile technology in terms of applications e.g. social media. The most popular ones were Facebook, Twitter, Linkedin, Google Drive and Google Calendar, Dropbox, YouTube, Skype. In these terms, mobile meant better communication and organization, accessible information, and entertainment but also time consuming aspects and privacy concerns.

"I am concerned about privacy: which kind of documents may I put on the cloud?"

"I already use my mobile to listen to podcasts of Spanish news. Mobile learning could be useful to me to improve my social media skills"

"I am not a very technological person. Technology is time consuming and I prefer speaking rather than writing"

In order to measure mobile behaviours at the workplace, interviewees were asked to match icons of devices to work-related tasks visualized on the collage (see fig. 2). This reflection helped understand how mobile is already embedded in their working life and encouraged the reflection on how can it be connected to staff development activities as well.

"In the field I have a lot of dead moments in between assignments. If I am for example in a boring context, I could have easily used my time for training."

"I would have done the security in the field training more eagerly at home on my Ipad instead of staying in the office until late"

"I would have appreciated a short assignment after some of the F2F trainings I took in the past, e.g. an sms interaction to gather feedback"

\subsection{Interpretation}

Building on the discovery findings, the interpretation phase consisted in finding main themes and translating them into actionable statements. Mobile learning has to be "on the spot" meaning that it has to be framed in a specific context, a concept not acknowledged by "anywhere, anytime". According to Parsons [8], it has to be taken into account that individuals are not always able to learn and that they rarely learn while physically moving. But it is true that they tend to take their learning tools with them to the most appropriate places. Therefore, it is important to understand how it will be possible to strategically use already available learning tools and integrate them into workplace learning initiatives. 


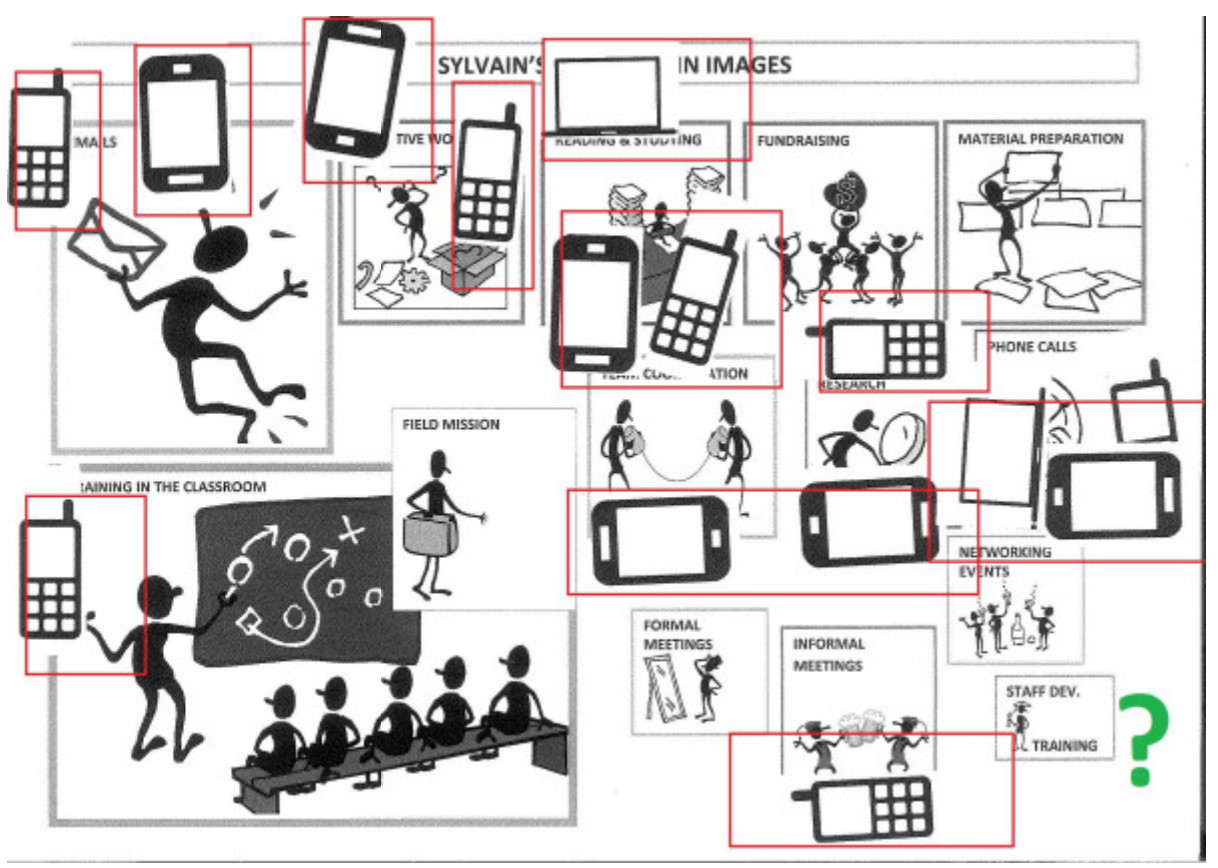

Fig. 2. To measure mobile behaviours, interviewees were asked to match icons of devices to work-related tasks and encouraged to reflect on how mobile can be connected to staff development activities

In order to understand to what extent mobile methods and tools can be integrated into ITC-ILO staff development activities, the adapted version of Engerstrom's framework [9] for analysing mobile learning was taken into account as it describes the dialectical relationship between technology and learning by including the following elements:

- the learners

- the learning goal

- the learning tools

- the learning context

- the communication among learners

- the learners' attitude/behaviour (motivation)

These six elements constitute a mobile learning ecosystem where each component interplays with the others, and cannot be considered in isolation. The match between the above mentioned framework components with the discovery phase findings resulted in the following three questions:

1. How will it be possible to create relevant mobile learning spots that augment informal learning and knowledge sharing (learning goal) by means of effective and 
improved interaction (communication) within and outside the organization (learning context)?

2. How can personal mobile devices (learning tools) contribute to the personalization and appropriation of learning experiences, where the " $\mathrm{m}$ " that usually stands for "mobile" can easily be perceived as "me"?

3. How will it be possible to increase motivation (learners' attitude) towards learning at work through game concepts?

\subsection{Ideation}

Building on the interpretation phase, main themes or actionable statements were identified. These led to considering three workplace-learning challenges that could be solved through mobile learning.

1. Improve knowledge sharing (furthermore "KS") and effective communication at the workplace;

2. Facilitate appropriation of learning experiences at the workplace;

3. Increase motivation towards learning at the workplace through game concepts.

The ideation phase consisted in designing practical solutions that took into account ITC-ILO staff learning needs and that were applicable within ITC-ILO staff development initiatives.

Table 1. Challenges vs. Ideas for future development

\begin{tabular}{|l|l|l|l|l|}
\hline Challenges/Ideas & $\begin{array}{l}\text { Idea 1: The } \\
\text { Community } \\
\text { of Practice } \\
\text { for the glocal } \\
\text { workplace }\end{array}$ & $\begin{array}{l}\text { Idea 2: The } \\
\text { CompassScape }\end{array}$ & $\begin{array}{l}\text { Idea 3: } \\
\text { Greening } \\
\text { the } \\
\text { Campus } \\
\text { workshop }\end{array}$ & $\begin{array}{l}\text { Idea 4: } \\
\text { The e- } \\
\text { Campus } \\
\text { Game- } \\
\text { board }\end{array}$ \\
\hline $\begin{array}{l}\text { KS \& effective } \\
\text { communication }\end{array}$ & $\mathrm{X}$ & $\mathrm{X}$ & $\mathrm{X}$ & $\mathrm{X}$ \\
\hline $\begin{array}{l}\text { Appropriation of } \\
\text { learning }\end{array}$ & $\mathrm{X}$ & $\mathrm{X}$ & $\mathrm{X}$ \\
\hline $\begin{array}{l}\text { Motivation } \\
\text { towards learning }\end{array}$ & & & & \\
\hline
\end{tabular}

Table 1 provides an overview of challenges and future development and implementation projects that can impact these challenges. We will discuss these approaches in the next section.

\section{Challenges and Ideas for Future Development}

\subsection{Community of Practice for the 'Glocal' Workplace}

In 2012 ITC-ILO started exploring the use of Yammer to improve cross-departmental communication but has not been rated as a successful tool for interaction and 
knowledge sharing at work. Interviewed staff stated that they did not see a clear strategy for using social networks within the organisation as ITC-ILO is perceived as a rather small organization. They additionally stated that they are already managing popular social media e.g. Facebook, Linkedin, Twitter, therefore they are resistant to use "yet another tool". Security concerns related to the online sharing of institutional documents on web 2.0 were highlighted. On the other hand, in 2013 ITC-ILO launched the institutional e-campus (http://ecampus.itcilo.org/), a Moodle-based virtual learning system increasing participants' access to learning opportunities beyond the classroom. The e-campus includes six learning modalities: tutored courses, self-learning, webinars, blended courses, academies and communities of practice (furthermore $\mathrm{CoP}$ ).

Although, the e-campus has been conceived as a platform to better reach and train participants all over the world, it is also a relevant tool for internal learning and knowledge exchange. In particular, the CoPs present the potential of facilitating KS and interaction at work as they are built inside an institutional platform, and focus on work-related topics. Until now the e-campus CoPs have not been explored yet. They can be recognised as an institutional channel to connect with colleagues and external professionals interested to the same domain. If CoP on ITC-ILO e-campus constitute an open network, they can also be used as a marketing tool to attract potential participants on ITC-ILO e-Learning catalogue.

After having conducted interviews on mobile behaviours and mobile learning strategies, it was noted that some staff is already familiar with lots of mobile devices for personal reasons (organization, entertainment, communication, and information) and look forward to make a link between technology and learning activities, others are considered rather resistant to technology even though they perceive its social importance. Mobile learning therefore generates both interest towards effective use of technology at work and frustration in terms of time consuming aspects related to new technology usage. In particular, there is a growing interest towards the effective use of such devices for training delivery inside and outside the classroom settings.

By focusing on the ITC-ILO e-campus CoPs rather than on an external web 2.0 tool, the focus of KS at work is shifted on a strategic institutional platform that is more and more becoming of central importance for ITC-ILO in terms of making learning opportunities available anytime and anywhere. A CoP on "Learning, Technology and Knowledge Management" was already created in 2013 but it was put to no use so far. The idea is to use it to better explore how mobile learning methodologies and technologies may be integrated into ITC-ILO learning modalities.

One of the challenging questions in the $\mathrm{CoP}$ is: "How do you make learning accessible anytime and anywhere?"

The Learning, Technology and Knowledge Management community will constitute an open network, accessible both from ITC-ILO staff and an external audience. This will facilitate the connection with the external world.

The primary target of the CoP is constituted by the 26 staff members who participated to the research project interviews. The secondary target is constituted by any other ITC-ILO staff interested in covering the topic. The tertiary target is constituted by external audience e.g. in March 2014, the University of Turin (Italy) organised a rounded table around the topic of mobile and education. The event 
gathered about twenty learning and development local professionals and researchers, including two ITC-ILO staff interested in exploring mobile learning potentials and ways to collaborate together. These twenty people will be invited to participate in the CoP.

The CoP will be launched through sharing the results from the interviews conducted for this research project which has the purpose to frame mobile learning concepts and behaviours. The results will be shared in a visual format. The objective of the CoP is to discuss and progressively learn how to integrate mobile technology into training delivery and validate mobile learning methods. In the last two years, the ITC-ILO Distance Education Learning Technology Applications (DELTA) has already produced substantial guidance on mobile methodologies and tools that facilitate learning beyond the classroom, before, during or after a face-to-face event. This experience will be used to make sure that ITC-ILO colleagues have access to such information in a contextualised environment.

In particular, this material will be located in the CoP "Toolkit box". In addition to this, the CoP will have a News forum, a main discussion forum and a database listing all the mobile methods. The main discussion forum will be used to encourage discussion on how can mobile learning be integrated before, during and after face-toface by providing practical tips and sharing best practices e.g. how can we inspire learners before a face-to-face (furthermore "F2F") session by means of mobile devices? How can we engage interaction during a F2F session by means of mobile devices? How can we gather feedback during a F2F session by means of mobile devices?

ITC-ILO staff will also be encouraged to rate the mobile methods listed in the database and share why they would or would not use such methods in the delivery of training activities. This task will be helpful for evaluating the relevance and efficacy of the developed mobile methods, increasing the overall quality of the mobile learning toolkit and encouraging ITC-ILO trainers to test mobile learning strategies.

Participation to the CoP initiative will be recognised through a visual and social tool, namely Open Badges by Mozilla Foundation [10]. Open badges are a digital representation of interests and learned skills, and can be displayed online e.g. the ecampus personal profile or social media, and offline as they are images.

Badges are considered mobile tools: "Get recognition for learning that happens anywhere. Then share it on the places that matter". Participants to the CoP will be entitled a "m-Learning" badge, facilitating the visualization of whom within the organisation is already familiar with such methodologies.

The evaluation of the CoP initiative will take place after three months from the launch and will take into account the qualitative and quantitative elements.

\subsection{CompassScape}

The CompassScape derives from the integration of two terms: the Compass and the Learnscape. The Compass is a project of the ITC-ILO centre's DELTA unit. DELTA is made up of a team of specialists who combine expertise in learning and knowledge sharing methodologies with professional backgrounds in international development. 
The Compass uses the metaphor of a navigational instrument to guide trainers through a repository of participatory learning, training and knowledge sharing methods. It orients the design of learning and training activities and provides inspiration in the search for useful, effective and relevant learning and training methodologies. It contains sixty participatory knowledge sharing methods and technologies to be used in any workshops or meeting.

These methods were developed and validated in workshops all over the world, conducted by the ITC-ILO and are currently available online (http://compass.itcilo.org/). The website is regularly updated with information on new methods or examples and best practices to better describe them.

Building on the information gathered by the DELTA unit on the use of Compass, there is a general resistance to use new methods and ITC-ILO staff keeps using always the same ones e.g. the World-café or Fishbowl, rather than learning and exploring the use of new learning strategies. On the other hand, observation in the field led to a particular reflection on the use of methods within ITC-ILO workplace settings. In February 2014, the Information Communication Technology Services (ICTS) requested to be trained by DELTA on the Compass methods and their potential use for internal decision-making procedures. Eight ICTS members attended an interactive session facilitated by DELTA where they were involved in identifying suitable Compass methods that would match typical ICTS scenarios. As a result, Compass methods are perceived to be relevant not only for trainers but also for other ITC-ILO staff involved in problem-solving and internal decision-making.

Finally the learnscape concept focuses on how does the architecture influence learning and training activities and how can physical spaces be optimized to facilitate the appropriation of learning experiences. The DELTA unit is currently conducting research on this matter by trying to transform the traditional campus training settings in an environment conducive to learning The CompassScape initiative was born by matching workplace learning issues and influence of physical space on learning. The micro-objective of the CompassScape initiative was framed in two questions: 1) how will it be possible to raise awareness towards the Compass methods? 2) how will it be possible to encourage the exploration of more methods?

The CompassScape was conceived as a specific itinerary that identifies areas inside the ITC-ILO campus where specific methods can be visualized and implemented. In particular, the objective is to identify under-used spaces such as the park or open spaces that until now serve as decoration rather than having a strong connotation for learning activities. In other words the CompassScape is the result of the integration between optimization of physical spaces and effective mobile learning strategies, by allowing learners to learn in a specific context in an informal way, through recognition of visual patterns and facilitating the appropriation of learning experiences through mobile devices. In this context, mobile learning is intended in its broad sense as learning beyond the classroom, extending the learning experience across informal spaces, and encouraging "out-of-the-room" reflection.

The CompassScape addresses primarily ITC-ILO staff involved in training activities (trainers and programme assistants involved with learning spaces organization); secondly ITC-ILO staff who is not regularly involved in training 
activities e.g. ICTS, and thirdly training participants involved in training of trainers activities who can get inspired by methods and apply them in their own context. The methodological approach adopted for the CompassScape is Harold Jarche's framework for professional development: seek-sense-share [10]. This framework consists of three steps: seeking important information and getting up-to-date, making sense and personalize the use of information, and finally sharing ideas and experiences with the network.

According to this framework, a time-framed initiative will be organized around the following phases:

- Exploring the ITC-ILO environment and identifying methods through visual patterns;

- Making sense of information through elaboration of visual data, use of mobile devices to access rich-media information e.g. videos through augmented reality.

- Sharing feedback through mobile devices by social media or software for engaging with a dispersed audience e.g. Polleverywhere

The implementation of the CompassScape initiative will consist in the identification of a set of methods from the Compass database. These methods will be visualized through patterns and associated to specific places within the campus. The idea behind is to encourage matching the implementation of certain methods in areas other than classroom settings or inspire staff to use new methods through visualization, reflection and personalization of information.

A map will be created where to locate a set of labels displaying visual methods. These labels will be enriched by information accessible through mobile devices e.g. a QR code directing to a short video description of the method. In addition to this, there will be instructions on how to share feedback about the methods e.g. sending SMS, use of microblogging and social media.

The CompassScape initiative will be tested through a time-framed initiative of 2 weeks, followed by an evaluation. The evaluation will take into account the following elements:

- Quantitative data e.g. number of staff registered to participate into the initiative, number of staff actively participating into the initiative by sharing feedback;

- Qualitative data e.g. analysis of comments and feedback, and formulation of suggestions of improvements.

\subsection{Mobile Learning for Improving Environmental Behaviours}

The idea is to concretely use mobile learning methods that were developed in the past 2 years by DELTA unit for selected projects and contextualise them into workplace learning initiatives. Moreover, this initiative links back with the CoP to be created in the framework of this research and intended to facilitate recognition and validation of mobile learning methods.

The ITC-ILO has been working intensively to improve its green soul in the recent years. For this reason a voluntary-based committee (the GCAG) was created in 2011. 
Its objective is to undertake an environmental review with external auditors, produce, monitor and evaluate an action plan, review the curriculum work to include environmental-related courses and activities, inform and involving staff, participants and service providers, and adopt an environmental code of conduct. Among the various initiatives, in February 2014 the centre was awarded the International EcoSchools Award Certificate and Green Flag for its achievements in improving the campus environmental performance and in promoting a sustainable approach to learning.

The GCAG realized that, despite all these efforts, the ITC-ILO staffs and the services know little about the green improvements and that greener personal behaviours would make the difference. On this basis, the GCAG designed a short workshop addressing staff and services.

The shape of the workshop will enable participants to explore existing information and report back on the several green initiatives undertaken on campus. Once participants have shared the current green picture of the ITC-ILO, they will be exposed to a wide range of informative and inspiring resources that will constitute the basis for a constructive discussion on how everybody can contribute to a greener campus. By adding a mobile component to one of the workshop sessions, it will be measured how learning can be extended beyond the classroom settings and amplify learning objectives.

The Greening the Campus Workshop was already designed and resulted in one day training, by including the following components: green IT strategy, green facilities, energy management, waste management, green procurement, green monitoring system and green learning. Mobile learning methodologies will be selected to suit the pre-learning, learning and follow-up learning phases. Those methods were already categorized by DELTA according to benefits, learning need moments and category (deliver content, assign tasks, gather feedback, provide support). The evaluation of this initiative will be made through the comparison with sessions implemented without using mobile learning methods in order to measure whether mobile can really be an added value and have an impact on overall learning objectives. We will also build on related projects and experiences at other locations for this topic [12].

\subsection{The e-Campus Game-Board: Applying Game Concepts to e-Learning Solutions}

The ITC-ILO e-campus project starts from a forward looking vision that will help the centre to position itself better in the e-Learning landscape.The e-campus supports different type of activities and not exclusively e-learning, namely self-guided elearning, tutor-based e-learning, on-line communities of practices, short promotional open educational resources and relevant ILO knowledge products. To convince colleagues moving to a centralized e-Learning platform, a series of incentives were presented such as decreasing investment in staff time when managing activities in the central e-campus; the benefit of using actual features that are currently not available in individual department platforms (webinars, mobile learning,); higher visibility in communication and promotion in contrast with decentralized learning products. 
In order to accompany the transition phase to a centralized platform, a series of training activities were planned targeting managerial and administrative staff to get familiar with the e-campus features. Within this initiative, the concept of mobile learning will constitute an additional learning component supporting staff training activities during the transition phase. In the discovery phase, it was noted that mobile learning is not only associated with mere technology but also with learning across contexts, flexible and informal learning modalities, and finally tools that enable learning at the moment of need enabling knowledge application, reflection and collaboration.

The e-Campus game-board initiative will focus on addressing workplace learning needs (building internal e-Learning capacity) through making available to ITC-ILO staff a tool that facilitates decisions about e-Learning processes. Building e-Learning courses can be time-consuming and costly, therefore the e-Campus game-board will not constitute a technical training on how to use features on the online platform or getting to better know the online environment. It will rather be focusing on selecting the right e-Learning modality and its suitable components. For example, focusing on sharing information or changing performance, keeping it simple or building a complex structure etc. The primary target of this initiative will be trainers belonging to different department; secondly staff involved with practical use of the online platform, dealing with content update, participants' registration or technical issues.

As part of the e-campus project, an appropriate learning management system was selected through a benchmarking exercise, which opted for an open source platform, namely Moodle. The e-Campus game-board initiative will be informed by already existing literature on how to integrate the Bloom's Taxonomy into Moodle learning management system. In particular, inspiration came from the visual Moodle teachers' guide created by Joyce Seitzinger [11], which allows them to compare the functionalities and pedagogical advantages of some standard Moodle tools with the different levels of Bloom Taxonomy, and finally leading to a comprehensive decision about e-Learning structure.

In order to create a customised e-Campus version, the following steps will be taken into account:

- Analyse the e-campus delivery modalities

- Create scenarios for each e-Learning modality and build a questions' guide

- Link Bloom's Taxonomy levels with e-Learning scenarios

- Create a list of e-campus functionalities that serve the different e-Learning scenarios

Bloom Taxonomy levels and e-Learning delivery modalities will be identified through different coloured cards, containing questions, visuals or description. Through the e-Campus game-board, staff will be encouraged to reflect on how to reach learning needs and build suitable e-Learning. The e-Campus game-board is meant to work out of formal training sessions, during departmental decision-making processes related to e-Learning delivery. Moreover, it can be used as a tool to describe how the e-Campus works to external ITC-ILO partners that want to jointly deliver e-Learning. 


\section{Discussion and Conclusion}

In this paper we attempted to show ITC-ILO efforts in creating a learning culture through a human-centred and personalised approach which tackles concrete workplace learning needs.

By integrating the results from the staff learning needs analysis, targeted interviews and observation on the field, it was possible to collect information around the ways staff engages with workplace training activities and inspiration about their use of mobile technology.

Understanding and interpreting their needs was a crucial step that helped rethink workplace learning delivery, shifting from traditional towards informal opportunities. Additionally, the paper outlines potential connections of mobile learning strategies with staff development learning activities, where the intention is to make strategic use of available mobile technology to augment continuous learning at work. In order to improve knowledge sharing, facilitate appropriation of learning experiences and increase motivation towards learning at the workplace, four ideas were identified: 1) the community of practice for the glocal workplace, 2) the CompassScape, 3) Greening the Campus workshop, 4) the e-Campus game-board. As part of the design thinking methodological approach used within this research, ideation will be followed by experimentation of working prototypes. The implementation of the above mentioned activities will take place approximately between June and November 2014. The outputs that will result from the implementation will be the task of a future paper.

Acknowledgement. The "M-Workplace learning @ ITC-ILO" research project is cofunded by the Italian Fondazione Goria and the International Training Centre of the International Labour Organisation (ITC-ILO) through the "Master dei Talenti per la Società Civile" fellowship programme. The total duration is of eighteen months starting in November 2013 and to be implemented as follows: twelve months at the Distance Education Learning and Technology Applications (DELTA) unit of the ITCILO in Turin, and the final six months at the Welten Institute of the Open University of the Netherlands.

\section{References}

1. http://www.itcilo.org/en/the-centre

2. http://mobile.itcilo.org

3. Parker, J.: Mobile Learning for Africa. Politecnico di Milano, Milan (2011)

4. IDEO, Riverdale Country School: Design Thinking for Educators Toolkit, pp. 11-14 (2013)

5. Pimmer, C., Pachler, N.: Mobile Learning in the Workplace: Unlocking the Value of Mobile Technology for Work-Based Education. In: Ally, M., Tsinakos, A. (eds.) Increasing Access to Mobile Learning, ch. 14, pp. 193-203. Commonwealth of Learning and Athabasca University, Vancouver (2014)

6. Gottfredson, C., Mosher, B.: Innovative Performance Support: Strategies and Practices for Learning in the Workflow. McGraw-Hill, New York (2011) 
7. Sharples, M., Taylor, J., Vavoula, G.: Towards a Theory of Mobile Learning, Centre for Educational Technology and Distance Learning, University of Birmingham (2005)

8. Parsons, D.: The Future of Mobile Learning and Implications for Education and Training. In: Ally, M., Tsinakos, A. (eds.) Increasing Access to Mobile Learning, ch. 16, pp. 217-229. Commonwealth of Learning and Athabasca University, Vancouver (2014)

9. Sharples, M., Taylor, J., Vavoula, G.: A Theory of Learning for the Mobile Age. In: Andrews, R., Haythornthwaite, C. (eds.) The Handbook of E-Learning Research, London, pp. 221-247 (2007)

10. http://www. openbadges.org

11. Jarche, A.: Seek Sense Share, Creative Commons (2012), http://www.jarche.com

12. Kalz, M., Börner, D., Ternier, S., Specht, M.: Mindergie: A pervasive learning game for pro-environmental behaviour at the workplace. In: Wong, L.-H., Milrad, M., Specht, M. (eds.) Seamless Learning in the Age of Mobile Connectivity. Springer, Heidelberg (2014)

13. Seitzinger, J.: Moodle Tool Guide for Teachers, Creative Commons (2010),

http://www. cats-pyjamas.net/ 